This is an author produced version of a paper published in International journal of geriatric psychiatry. This paper has been peer-reviewed but does not include the final publisher proof-corrections or journal pagination.

Citation for the published paper:

Passant, Ulla and Rosén, Ingmar and Gustafson, Lars and Englund, Elisabet "The heterogeneity of frontotemporal dementia with regard to initial symptoms, qEEG and neuropathology"

Int J Geriatr Psychiatry. 2005 Oct;20(10):983-8

http://dx.doi.org/10.1002/gps.1388

Access to the published version may require journal subscription.

Published with permission from: Wiley 


\section{The heterogeneity of frontotemporal dementia with regard to initial symptoms, qEEG and neuropathology.}

Ulla Passant ${ }^{1}$, Ingmar Rosén ${ }^{2}$, Lars Gustafson ${ }^{1}$, Elisabet Englund ${ }^{3}$

Departments of Psychogeriatrics ${ }^{1}$, Neurophysiology ${ }^{2}$ and Pathology ${ }^{3}$, Lund University Hospital, Sweden.

Running title: The heterogeneity of frontotemporal dementia

Corresponding address:

Ulla Passant

Department of Psychogeriatrics

University Hospital

S 22185 Lund

Sweden

E-mail ulla.passant@skane.se

Tel 4646177454

Fax 4646177457 


\begin{abstract}
Ten patients with neuropathologically verified frontotemporal dementia (FTD) were analysed for neuropathological features in relation to first presenting and dominating symptoms, age at onset and duration of dementia, as well as to EEG/ quantitative EEG.

Cases with a late onset ( $>65$ years) initially presented language disturbances, while the early onset group (<65 years) showed predominantly behavioural symptoms and mood alterations as early features.

The late onset group presented combined cortical-subcortical degeneration including white matter pathology, while early onset cases showed pathology predominantly in the cortex.

EEG was normal in the late onset group, while it was mildly and variably abnormal in those with early onset.

Within this small sample of clinical and neuropathological FTD, cases with late vs. early onset differed with respect to initial symptoms, EEG findings and regional distribution of brain pathology.
\end{abstract}

Keywords: Frontotemporal dementia, initial symptoms, age, variability, EEG, neuropathology 


\section{Introduction}

Frontotemporal dementia (FTD) (Lund-Manchester groups, 1994) constitutes the prototypical behavioural disorder arising from frontotemporal degeneration and atrophy, first described by Arnold Pick (Pick 1892). Pure Pick's disease is however rare and diagnosed in only a subgroup of post mortem studied FTD. Frontal lobe degeneration of non Alzheimer type, (FLD) is more common within this group of degenerative dementias. It was described neuropathologically and clinically in 1987-88 (Brun, 1987; Gustafson, 1987; Neary et al., 1988). This entity corresponds to dementia lacking distinctive histology (Knopman et al., 1990) and to "dementia with nonspecific pathology" (Kim et al., 1981; Clarke et al., 1986).

The FTD group, according to the Lund-Manchester consensus criteria (1994), comprises three clinico-pathological entities; Pick's disease, FLD and motor neuron disease with dementia (MNDD). The consensus statement provided diagnostic guidelines to improve the clinical and pathological recognition of FTD. A subsequent revised consensus on clinical criteria in 1998 (Neeary et al., 1998 ) identified three major clinical syndromes with frontotemporal lobar degeneration (FTLD); FTD with progressive change in personality coupled with affective symptoms and reduced verbal output, progressive nonfluent aphasia (PA) a disorder of expressive language, and semantic dementia with breakdown in semantic knowledge. In spite of this differential classification, several studies suggested that changes in behaviour and personality are also common in PA and semantic dementia (Hodges et al., 1998; Kertesz et al., 1999; Snowden et al., 2001).

The age of onset in FTD usually is between 40 and 65 years (Gustafson, 1987; Neary, 1988; Miller, 1991; Knopman, 1990) though cases above 70 have been reported by several groups (Miller et al., 1991; Gregory and Hodges, 1996).

The clinical characteristics of FTD are not uniform although most patients share the major features of alterations in personality and social conduct, affective symptoms and disturbances of expressive speech.

Structural and functional imaging usually show predominant frontal and/or frontotemporal pathology (Lund-Manchester groups, 1994), often with an asymmetrical engagement of the hemispheres (Miller et al., 1999).

The electroencephalogram (EEG), when visually interpreted, has been reported to be normal or only slightly abnormal in a substantial proportion of FTD patients, despite clinically advanced dementia (Johannesson et al., 1979; Yener et al., 1996; Pasquier et al., 1999). This is at variance with the EEG findings in Alzheimer's disease. A higher proportion of abnormal EEG was recently reported by Chan et al (2004) and the frequency of abnormal EEG findings seems to increase late in the disease (Pasquier et al., 1999).

Quantitative spectral EEG analysis (qEEG) has shown preserved alpha activity in FTD, in contrast to Alzheimer patients and a moderate increase of low frequency activity, particularly theta activity (Stigsby et al., 1981; Rosén et al., 1993; Yener et al., 1996; Besthorn et al., 1996). A decrease in beta activity has been reported by Lindau et al (2003).

No attempt has so far been made to relate visual EEG or qEEG to specific clinical features and neuropathology in FTD.

Brain pathology includes a frontotemporal atrophy, sometimes reaching to include anterior parts of the parietal lobes and in some cases with a notable hemispheric asymmetry. Microscopically, there is neuronal degeneration with cell atrophy and loss, a reactive gliosis and, less conspicuously, a laminar microvacuolation. (Brun, 1987; Mann and South, 1993; Lund-Manchester groups, 1994). The degeneration involves the outer three cortical laminae and may extend more deeply to cover all layers in advanced cases. 
In spite of shared major features of structural brain changes in FTD, there is a marked variability between individual cases in their neuropathological presentation. Furthermore the correlation between clinical and neuropathological features varies with regard to severity and regionality. Several special microscopical findings, including immunohistochemically classified neuronal inclusions are recognized albeit as yet without consistent correlates in the clinical symptom profile.

The aim of this study was to describe and analyze the neuropathological features in relation to the initial and predominating symptoms as reported by family members, age at onset and duration of dementia, as well as to quantified EEG.

\section{Materials and Methods}

The 10 FTD patients were all part of the Lund Longitudinal Dementia Study (Brun and Gustafson, 1993); included were only patients with a neuropathologically verified FTD from 1998 to 2003, on whom the medical records contained data from a close informant about initial symptoms. EEG and qEEG recordings, required for inclusion, were analysed. Patient demographic data are given in Table 1 .

At the time of EEG, 3 patients (cases 6, 7, 8) used psychotropic drugs. The dosage was however small and therefore not considered to enhance or otherwise influence the EEG pattern.

qEEG was extracted by FFT analysis from 20 minute routine digital EEG (19 channels according to the 10-20 system, sampling frequency $256 \mathrm{~Hz}$ ) recorded with Nervus TM equipment. In order to certify that EEG was recorded with the patient fully awake, $10 \mathrm{sec}$ epochs of artefact free EEG were selected for analysis which were recorded in the eyes-closed situation within $20 \mathrm{sec}$ after interaction with the patients either by verbal communication, or following eye closure upon command.

The FFT analysis was made in the common average mode and logarithmic absolute power as well as relative power were calculated for each quadrant of the head: left anterior (F3, F7,T3, $\mathrm{C} 3)$, right anterior $(\mathrm{F} 4, \mathrm{~F} 8, \mathrm{~T} 4, \mathrm{C} 4)$, left posterior $(\mathrm{P} 3, \mathrm{~T} 5, \mathrm{O} 1)$, right posterior $(\mathrm{P} 4, \mathrm{~T} 6, \mathrm{O} 2)$.

Z-scores for absolute and relative power for delta $(0,5-4 \mathrm{~Hz})$, theta $(4-8 \mathrm{~Hz})$, alpha $(8-13 \mathrm{~Hz})$ and beta (13-32 Hz) EEG activity as a result of statistical comparison with a group of 37 normal subjects (age 44-81) were calculated for each quadrant. In this report only average values for all four quadrants are given. Comparisons between early and late onset groups were made (Mann-Whitney).

In the postmortem investigation, the entire brains were fixed in formaldehyde solution, cut in $\mathrm{cm}$-thick coronal brain slices and processed for sectioning at $6 \mu \mathrm{m}$. The whole brain sections were stained with hematoxylin-eosin and with Luxol Fast Blue for myelin. Sampled small sections were immunohistochemically stained.

The neurodegenerative changes in the cerebral cortex were mapped and semiquantitatively graded as mild, moderate or severe. White matter pathology as well as the neurodegenerative involvement of the limbic regions and the basal ganglia was evaluated and semiquantitatively graded in a similar way.

\section{Results}

The individual FTD cases were ranked according to age at onset, which varied between age 46 and 84 (Table 1). The duration of the disease varied between $2-10$ years.

When dichotomized into groups with onset before or after age 65 , different profiles appeared with regard to initial and dominating symptoms, as reported by a close relative. In the early 
onset group, initial symptoms reported were alterations in mood and personality, whereas language disturbances dominated in the late onset group.

All patients had been examined and diagnosed at other clinics or by a primary care physician before referral to the Psychogeriatric department. Only one patient had initially been diagnosed as suspected dementia, (case 7), while cases $\mathrm{nr}$ 1-4 and $\mathrm{nr} 9$ were diagnosed as depression. Cases $\mathrm{nr} 5,6,8$ and 10 were initially judged to suffer from a cerebrovascular disorder or aphasia.

By the subsequent investigation at our department, 9 patients were clinically diagnosed as FTD (Lund Manchester criteria, 1994) and one patient (case 10) was diagnosed as vascular dementia with a frontal clinical profile, however later neuropathologically identified as FTD.

EEG investigation in patients with early disease onset (cases 1-5) showed higher values of relative theta power, whereas patients with late onset all had normal $\mathrm{qEEG}$ values (cases 6, 810 ) and normal EEG on visual inspection (cases 6-10) (Fig 1). Three patients $(2,3,4)$ had relative theta power $Z$-scores $>2$. There was in addition, a group difference regarding relative beta power (Table 2). Although not significant, the absolute theta activity was higher in the early onset group, which indicates that the high relative theta values in this group is a result of increased theta power, possibly in combination with a decrease of beta power. Furthermore, the peak frequency of the posterior dominant activity was lower in the early onset group. The duration of disease at time of qEEG did not differ between the two groups.

The neuropathological data are shown in table 3. All cases exhibited neurodegenerative changes accentuated in the frontal or frontal and anterior temporal cortex, although in one case (case 5), the relative differences between regions were smaller than in all other cases. Hemispheric asymmetry was seen in both groups ( 7 of 10 cases), with an overall predominance of left over right accentuation (5/7).

All cases exhibited frontotemporal lobe degeneration and two cases (4 and 6) showed some of the additional pathological features of corticobasal degeneration, which in its full extent encompasses insular engagement, tau-positive white matter glia and tau-positive cortical neurons.

Neocortical pathology dominated in the early onset cases, while in the late onset group there was prominent pathology also in the basal ganglia and in the white matter.

Microscopically, there were neuronal atrophy and reduced neuronal numbers in cortical laminae II and III. A mild and only segmentally notable microvacuolation was seen in layer II and there was reactive gliosis with enlarged astrocytes and activated microglia occurring throughout the entire cortical width in most advanced regions. Severity of gliosis and neuronal loss did not consistently correlate.

In the late onset group (cases 6-10) white matter changes occurred in the frontal and/or temporal lobes, subjacent to the areas of accentuated cortical pathology. There was mild, moderate or advanced gliosis, as well as axonal and myelin reduction, but no focal infarcts and only limited vascular pathology.

Limbic pathology (cingulate, amygdalar and hippocampal) was seen in both groups, it varied between individuals.

Basal ganglia pathology, slightly predominating in the late onset group, included neuronal degeneration in striatum and thalamus. 


\section{Discussion}

The studied group represents but a small sample of FTD patients in Lund, Sweden. The group was however investigated in a standardized way and from the assembled data, the initial clinical symptoms reported by the family, EEG patterns and neuropathological profiles were presented.

One striking feature is the variability within this small sample, a variability regarding not only age of onset and duration, but also in dichotomized presentation between early and late onset in terms of initial presenting symptoms, EEG profiles and neuropathological patterns.

The early onset group described in variable terms of initial symptoms (reported by the family), all exhibited symptoms related to a change in personality and emotional capacity, whereas the late onset group all had language disturbances of various types (Table 1). These different language disturbances were however reported by the relatives as being early features and were not neuropsychologically evaluated with respect to aphasia subtypes. Our results can therefore not be compared to more comprehensive presentations on the relations between language disturbances and regional brain pathology (Snowden et al., 1992, Hodges et al., 1992, Kertez et al., 1994, Rosen et al., 2002).

Neuropathologically, we can only state that eventually, there was a similar regional distribution of cortical changes in both groups, with a slight predominance of frontal over temporal pathology. Hemispheric asymmetry did not seem to account for any particular profile in this material. The subcortical pathology, stronger in the late onset cases, may have contributed to a clinical presentation with a less obvious behavioral disorder. An altered clinical profile is observed also in other dementing diseases with progressive subcortical pathology (Gustafson and Passant 2004). Besides pathology of the basal ganglia, white matter pathology is frequent, albeit underrecognized in FTD (Englund and Brun, 1987; Larsson et al., 2000, Larsson et al., 2004) and the present findings may indicate that white matter changes here influenced the early reported clinical symptoms.

EEG has not been widely used in FTD, although a normal or near normal visual EEG has been considered as a criterion of a degenerative disorder of non-Alzheimer type (LundManchester groups, 1994). The results of qEEG in this study, showing an increase of relative theta power and a well preserved alpha power, is in agreement with most previous reports (Stigsby et al., 1981, Rosén et al.,1993, Yener et al., 1996, Besthorn et al., 1996) but different from those of Lindau et al., 2003, who found mainly a decrease of high frequency EEG components. Each of these studies, including the present investigation, comprised small patient groups. Nevertheless, the clinical and electrophysiological heterogeneity emerges as an interesting feature.

Early onset FTD patients exhibited a clear at least moderately strong qEEG pathology, while the late onset cases did not. The neuropathological alterations, in the end of disease, were dominated by cortical frontal and temporal abnormality and less subcortical pathology than the late onset group. It might be speculated that the superficial cortex in frontotemporal areas was more functionally affected by the disease in the younger group at the time of the EEG examination.

\section{Conclusion}

Within a group of clinically and neuropathologically diagnosed cases of FTD, early vs. late onset individuals presented different symptoms at onset, dissimilar EEG profiles during disease and they diverged with regard to regional distribution of brain pathology. 
These findings demonstrate the great variability among individuals within the FTD spectrum. They point towards possibilities to further refine differential diagnoses within this disease entity.

\section{Acknowledgment}

This study was supported by the Swedish Alzheimer Foundation, Stiftelsen Ellen och Henrik Sjöbrings Minnesfond, the Swedish Research Council (project no 3950 and 084) and the County Council of Region Skåne.

\section{Keypoints}

- FTD cases with early onset ( $<65$ years) vs. late ( $>65$ years) differ with respect to initial symptoms as reported by the family, EEG finings and brain pathology.

- They exhibit a great clinical and neuropathological heterogeneity important to recognize in the diagnostic procedure. 


\section{References}

Besthorn C, Sattel H, Hentschel F, Daniel S, Zerfass R, Förstl H. 1996. Quantitative EEG in frontal lobe dementia. J Neural Transm Suppl 47: 169-181.

Brun A, Gustafson L. 1993. The Lund Longitudinal Dementia Study: A 25-year perspective on neuropathology, differential diagnosis and treatment. In Alzheimer's Disease: Advances in Clinical and Basic Research, Corain B, Iqbal K, Nicolini M, Winblad B, Wisniewski H, Zatta P (eds). John Wiley \& Sons Ltd ; 3-18.

Brun A. 1987. Frontal lobe degeneration of non-Alzheimer type. I. Neuropathology. Arch Gerontol Geriat 6: 193-208.

Clarke AW, White III CL, Manz HJ, Parhad IM, Curry B, Whitehouse PJ, Lehmann J, Coyle JT. 1986. Primary degenerative dementia without Alzheimer pathology. Can J Neurol Sci 13:462-470.

Chan D, Walters RJ, Sampson EL, Schott JM, Smith SJ, Rossor MN. 2004. EEG abnormalities in frontotemporal lobar degeneration. Neurology 62: 1628-1630.

Englund E, Brun A. 1987. Frontal lobe degeneration of non-Alzheimer type. White matter changes. Arch Gerontol Geriatr 6: 235-243.

Gregory CA, Hodges JR. 1996. Clinical features of frontal lobe dementia in comparison with Alzheimer's disease. J Neural Transm 47: 103-123.

Gustafson L. 1987. Frontal lobe degeneration of non-Alzheimer type. II. Clinical picture and differential diagnosis. Arch Gerontol Geriat 6: 209-223.

Gustafson L, Passant U. 2004. Clinical pathological correlates. In Cerebrovascular Disease, Cognitive Impairment and dementia, Chiu E, Gustafson L, Ames D, Folstein MF (eds). Dunitz; 197-210.

Hodges JR, Garrard P, Patterson K. 1998. Semantic dementia. In Pick's Disease and Pick Complex, Kertesz A, Munoz DG (eds).New York: Wiley-Liss, Inc; 83-104.

Hodges JR, Patterson K, Oxbury S, Funnell E. 1992. Semantic dementia; Progressive fluent aphasia with temporal lobe atrophy. Brain 115: 1783-1806.

Johannesson G, Hagberg B, Gustafson L, Ingvar DH. 1979. EEG and cognitive impairment in presenile dementia. Acta Neurol Scand 59: 225-240.

Kertesz A, Davidson W, Munoz DG. 1999. Clinical and pathological overlap between frontotemporal dementia, primary progressive aphasia and corticobasal degeneration: The Pick complex. Dement Geriatr Cogn Disord 10(suppl 10): 46-49.

Kertesz A, Hudson L, Mackenzie IRA, Munoz DG. 1994. The pathology and nosology of primary progressive aphasia. Neurology 44: 2065-2072.

Kim RC, Collins GH, Parisi JE, Wright AW, Chu YB. 1981. Familial dementia of adult onset with pathologic findings of a "non-specific" nature. Brain 104: 61-78.

Knopman DS, Mastri AR, Frey WH, Sung JH, Rustan T. 1990. Dementia lacking distinctive histologic features: A common non-Alzheimer degenerative dementia. Neurology 40: 251-256.

Larsson E-M, Englund E, Sjöbeck M, Lätt J, Brockstedt S. 2004. MRI with diffusion tensor imaging post mortem at 3.0 Tesla in a patient with Fronto-Temporal Dementia. Dement Geriatr Cogn Disord 17: 316-319.

Larsson E-M, Passant U, Sundgren PC, Englund E, Brun A, Lindgren A, Gustafson L. 2000. Magnetic resonance imaging and histopathology in dementia, clinically of frontotemporal type. Dement Geriatr Cogn Disord 11: 123-134.

Lindau M, Jelic V, Johnsson SE, Andersen C, Wahlund LO, Almkvist O. 2003. Quantitative EEG abnormalities and cognitive dysfunction in frontotemporal dementia and Alzheimer's disease. Dement Geriatr Cogn Disord 15: 106-114.

Mann DMA, South PW. 1993. The topographic distribution of brain atrophy in frontal lobe dementia. Acta Neuropath 85: 335-340. 
Miller BL, Cummings JL, Villanueva-Meyer J, Boone K, Mehringer CM, Lesser IM, Mena I. 1991. Frontal lobe degeneration: Clinical, neuropsychological and SPECT characteristics. Neurology 41: 1374-1382.

Miller BL, Gearhart R. 1999. Neuroimaging in the diagnosis of frontotemporal dementia. Dement Geriatr Cogn Disord 10(suppl 1): 71-74.

Neary D, Snowden JS, Gustafson L, Passant U, Stuss D, Black S, Freedman M, Kertesz A, Robert PH, Albert M, Boone K, Miller BL, Cummings J, Benson DF. 1998. Frontotemporal lobar degeneration. A consensus on clinical diagnostic criteria. Neurology 51: 1546-1554.

Neary D, Snowden JS, Northen B, Goulding PJ. 1988. Dementia of frontal lobe type. J Neurol Neurosurg Psychiatry 51: 353-361.

Pasquier F, Lebert F, Lavenu I, Guillaume B. 1999. The clinical picture of frontotemporal dementia: Diagnosis and follow-up. Dement Geriatr Cogn Disord 10(suppl 1): 10-14.

Pick A. 1892. Über die Beziehungen der senilen Hirnatrophie zur Aphasie. Prager Med Wochenschr 17: 165-167.

Rosén I, Gustafson L, Risberg J. 1993. Multichannel EEG frequency analysis and somatosensoryevoked potentials in patients with different type of dementia. Dementia 4: 43-49.

Rosen HJ, Kramer JH, Gorno-Tempini ML, Schuff N, Weiner M, Miller BL.. 2002. Patterns of cerebral atrophy in primary progressive aphasia. Am J Geriatr Psychiatry 10: 1; 8997.

Snowden JS, Bathgate D, Varma A, Blackshaw A, Gibbons ZC, Neary D. 2001. Distinct behavioural profiles in frontotemporal dementia and semantic dementia. $J$ Neurol, Neurosurg Psychiatry 70: 323-332.

Snowden JS, Neary D, Mann DMA, Goulding PJ, Testa HJ. 1992. Progressive language disorder due to lobal atrophy. Ann Neurol 31: 174-183.

Stigsby B, Johannesson G, Ingvar DM. 1981. Regional EEG analysis and regional cerebral blood flow in Alzheimer's disease and Pick's disease. Electroencephalogr Clin Neurophysiol 51: 537-547.

The Lund and Manchester Groups. 1994. Clinical and neuropathological criteria for frontotemporal dementia. J Neurol Neurosurg Psychiatry 10: 416-418.

Yener GG, Leuchter AF, Jenden D, Read SL, Cummings JL Miller BL. 1996. Quantitative EEG in frontotemporal dementia. Clin Electroencephalogr 27: 61-68. 
Table 1. Demographic characteristics

\begin{tabular}{|c|c|c|c|c|}
\hline Case & Sex & $\begin{array}{l}\text { Age at } \\
\text { onset }\end{array}$ & Initial symptoms reported by the family & $\begin{array}{l}\text { Duration } \\
\text { (y) }\end{array}$ \\
\hline 1 & M & 46 & Withdrawal, apathy, "seemed depressed" & 6 \\
\hline 2 & M & 51 & $\begin{array}{l}\text { Emotional lability, mood shifting, } \\
\text { impulsivity }\end{array}$ & 10 \\
\hline 3 & M & 53 & $\begin{array}{l}\text { Lost interest in work/family, withdrawal, } \\
\text { apathy }\end{array}$ & 9 \\
\hline 4 & M & 56 & Anxiety, "seemed depressed" & 6 \\
\hline 5 & M & 63 & $\begin{array}{l}\text { Emotional unconcern, loss of empathy, } \\
\text { withdrawal }\end{array}$ & 9 \\
\hline 6 & $\mathrm{M}$ & 66 & Word finding difficulties & 8 \\
\hline 7 & F & 68 & $\begin{array}{l}\text { Incoherent speech, perseverations, } \\
\text { inappropriate behaviour }\end{array}$ & 5 \\
\hline 8 & M & 70 & $\begin{array}{l}\text { Problems with using correct words (can } \\
\text { not use the phone) }\end{array}$ & 3 \\
\hline 9 & M & 71 & $\begin{array}{l}\text { Reduced spontaneous conversation } \\
\text { Verbal output decreased }\end{array}$ & 9 \\
\hline 10 & $\mathrm{~F}$ & 84 & Anxiety, word finding difficulties & 2 \\
\hline
\end{tabular}

Table 2. qEEG - Comparisons between groups

\begin{tabular}{lcccc}
\hline & Case $1-5$ & Case $6,8,9,10$ & $Z$ & $\mathrm{Z}$ \\
\hline Peak frequency & $7,76(0,43)$ & $8,88(0,82)$ & $-2,3$ & 0,0174 \\
Rel delta & $18,44(11,55)$ & $21,57(7,01)$ & $-0,49$ & 0,62 \\
Rel theta & $33,9(8,92)$ & $15,55(2,88)$ & $-2,5$ & 0,0143 \\
Rel alpha & $32,52(6,61)$ & $34,22(10,83)$ & $-0,25$ & 0,81 \\
Rel beta & $15,13(4,70)$ & $28,65(8,02)$ & $-2,2$ & 0,0275 \\
log abs theta & $1,975(0,845)$ & $0,939(0,691)$ & $-1,5$ & 0,14 \\
log abs beta & $1,074(0,661)$ & $1,555(0,715)$ & $-0,735$ & 0,46 \\
\hline
\end{tabular}

(Mann-Whitney) Mean (SD) Mean (SD)

Table 3. Neuropathology

\begin{tabular}{cccccccc}
\hline Case & $\begin{array}{c}\text { Frontal } \\
\mathrm{cx}\end{array}$ & $\begin{array}{c}\text { Temporal } \\
\mathrm{cx}\end{array}$ & $\begin{array}{c}\text { Parietal } \\
\mathrm{cx}\end{array}$ & Asymmetry & $\begin{array}{c}\text { White } \\
\text { matter }\end{array}$ & Limbic & $\begin{array}{c}\text { Basal } \\
\text { ganglia }\end{array}$ \\
\hline 1 & ++ & ++ & - & $\mathrm{L}>\mathrm{R}$ & - & ++ & - \\
2 & + & + & - & $\mathrm{R}>\mathrm{L}$ & - & - & - \\
3 & +++ & ++ & + & $\mathrm{L}>\mathrm{R}$ & ++ & ++ & ++ \\
4 & + & + & - & $=$ & + & - & + \\
5 & ++ & ++ & ++ & $\mathrm{L}>\mathrm{R}$ & - & + & + \\
\hline 6 & ++ & + & - & $\mathrm{L}>\mathrm{R}$ & ++ & + & ++ \\
7 & + & + & - & $\mathrm{R}>\mathrm{L}$ & + & ++ & +++ \\
8 & ++ & ++ & + & $=$ & +++ & + & ++ \\
9 & +++ & ++ & - & $=$ & +++ & ++ & ++ \\
10 & +++ & ++ & ++ & $\mathrm{L}>\mathrm{R}$ & +++ & ++ & + \\
\hline
\end{tabular}

+ mild pathology; ++ moderate pathology; +++ severe pathology; - minimal engagement; L left; $\mathrm{R}$ right; = symmetrical engagement 
Figure 1

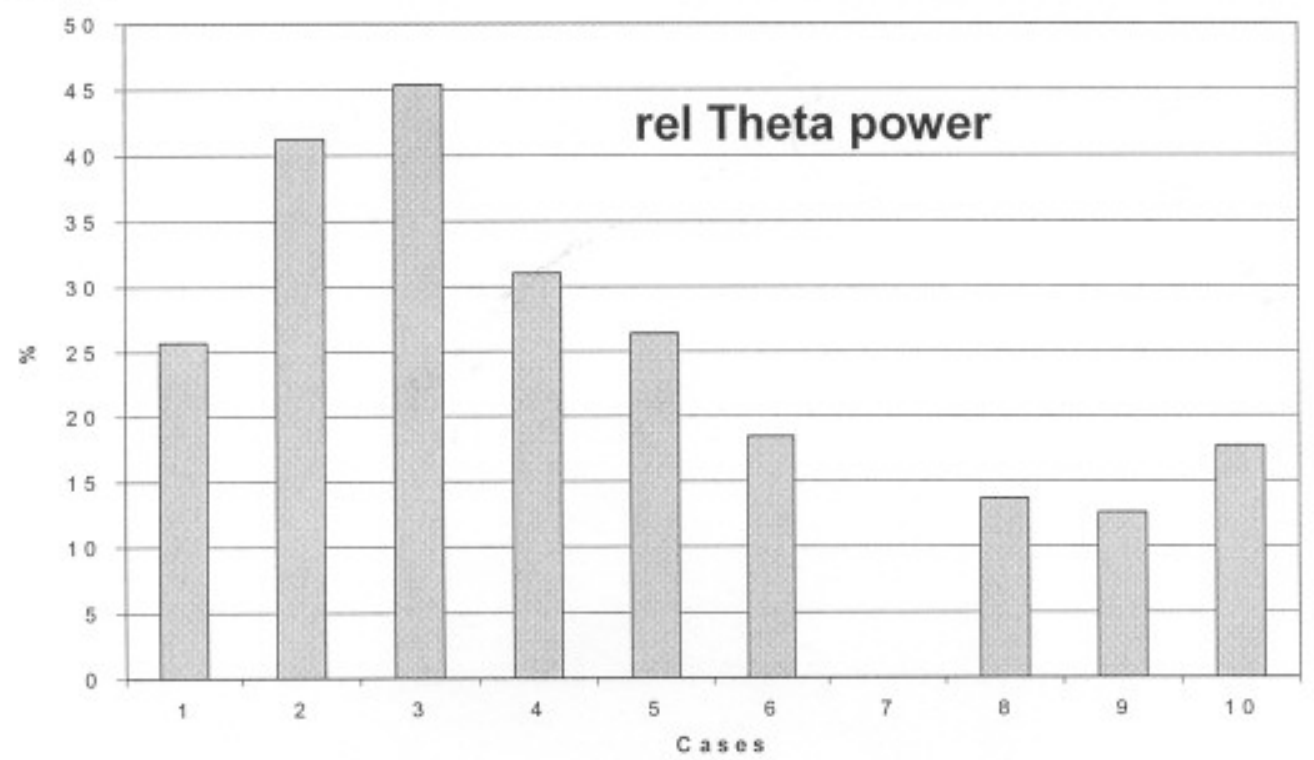

Relative EEG beta power in the individual cases sequenced in order of age at disease onset. qEEG was not performed in case 7 . 